\title{
Decentralized proportional-integral control with carbon addition for wastewater treatment plant
}

\author{
M. H. Husin ${ }^{1}$, M. F. Rahmat ${ }^{2}$, N. A. Wahab ${ }^{3}$ \\ ${ }^{1}$ Department of Electrical and Electronic Engineering, Faculty of Engineering, Universiti Malaysia Sarawak, Malaysia \\ ${ }^{2,3}$ School of Electrical Engineering, Faculty of Engineering, Universiti Teknologi Malaysia, Malaysia
}

\begin{tabular}{l}
\hline \hline Article Info \\
\hline Article history: \\
Received Jan 15, 2020 \\
Revised Mar 30, 2020 \\
Accepted May 13, 2020
\end{tabular}

Keywords:

Activated sludge

Aeration intensity

Control handle

Effluent quality

Proportional-integral control

Wastewater treatment

\begin{abstract}
Two main challenges in activated sludge wastewater treatment plant (WWTP) are cost and effluent quality, which has forced the wastewater treatment operator to find an alternative to improve the existing control strategy. The Benchmark Simulation Model No. 1 (BSM1) is applied as operational settings for this study. In BSM1, the standard control variables are the internal recirculation flow rate and the oxygen transfer rate. To improve the existing control strategy of BSM1, three alternative control handles are proposed, which are the individual aeration intensity control, carbon source addition and combination of both. The effect of each control handles in terms of the effluent violation, effluent quality, aeration cost, and total operational cost index are examined. The simulation result has shown that the individual control of aeration intensity improved the effluent quality index, and reduced the aeration, pumping, and total operational cost index when compared to the standard BSM1 control handle. Nonetheless, the addition of a fixed external carbon source has shown a significantly improved effluent quality with a lower number of total nitrogen violations as compared to the standard BSM1 control handles. Thus, the proposed control handles may be beneficial if applied in a real WWTP.
\end{abstract}

This is an open access article under the CC BY-SA license.

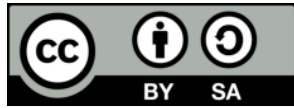

Corresponding Author:

M. H. Husin,

Department of Electrical and Electronic Engineering,

Faculty of Engineering, Universiti Malaysia Sarawak,

94300 Kota Samarahan, Sarawak, Malaysia.

Email: hhmaimun@unimas.my

\section{INTRODUCTION}

Challenges in activated sludge wastewater treatment plant (WWTP) are divide into two main groups which are to cut down the costs for operation, particularly the aeration energy and to maintain the effluent quality of wastewater treatment plant. The energy consumption may range from 30-50\% [1] of the total operating costs of the WWTP with more than half of the energy demand comes from the aeration section. The upsurges in the cost of energy escalated the cost even more. Standards are formed for the quality of effluent discharged from the WWTP to the rivers. Fine or penalty will be charged caused by the release of pollutants in the receiving water. Without a doubt, the WWTP are subject to large disturbances and uncertainty in the elements of the incoming wastewater. Not only the control design is difficult, but the modeling of WWTP is also a challenge due to the high dimensional and an outsized number of parameters [2]. There are a few technologies available used to control effluent discharge from WWTP. One of the common techniques is the activated sludge process (ASP) that make use of bacteria or microbes to oxidize the organic and non-organic matters in the wastewater. There are two steps involved in the process, which 
are nitrification and denitrification. Nitrification is a process where the ammonium is converted to nitrate under aerobic conditions. Denitrification, on the other hand, is a process of converting the nitrate into gaseous nitrogen under anoxic conditions. This two-step procedure is crucial to achieving efficient nitrogen removal in the ASP.

Conversely, the highly nonlinear and time-varying condition that exists in the dynamic behaviour of the biological nitrogen removal makes a complex relationship between control input and output variables [3]. Thus, in controller design for the ASP, troubles triggered by the interaction of control parameters are un-avoided. Hence, a decentralized controller is an option whereby the system is decomposed into several equivalent single loops. The decentralized controller has been applied in many industrial systems such as power systems [4], Heating, ventilation, and air conditioning (HVAC) [5] and many more. The BSM1 [6] is the first benchmark plant that is developed by the IWA Task Group on Benchmarking of Control Strategies for WWTPs. The BSM1 is a simulation setting made of five compartments activated sludge reactor comprising of non-aerated compartments (two anoxic tanks) and aerated compartments (three aerobic tanks). The plant layout of BSM1 is as shown in Figure 1. The plant mixes nitrification with pre-denitrification in a composition that is normally operated for attaining biological nitrogen removal in a full-scale plant. The arrangements are tailed by a secondary settler. The foremost two compartments are anoxic, the aerated compartment 3 and 4 have fixed oxygen transfer coefficient $\left(K_{a}=10, h^{-1}=240 \mathrm{~d}^{-1}\right)$ and forgoing compartment 5 has dissolved oxygen (DO) concentration regulated at $2 \mathrm{~g}(-\mathrm{COD}) \cdot \mathrm{m}^{-3}$ by control of $\mathrm{KL}_{\mathrm{a}}$.

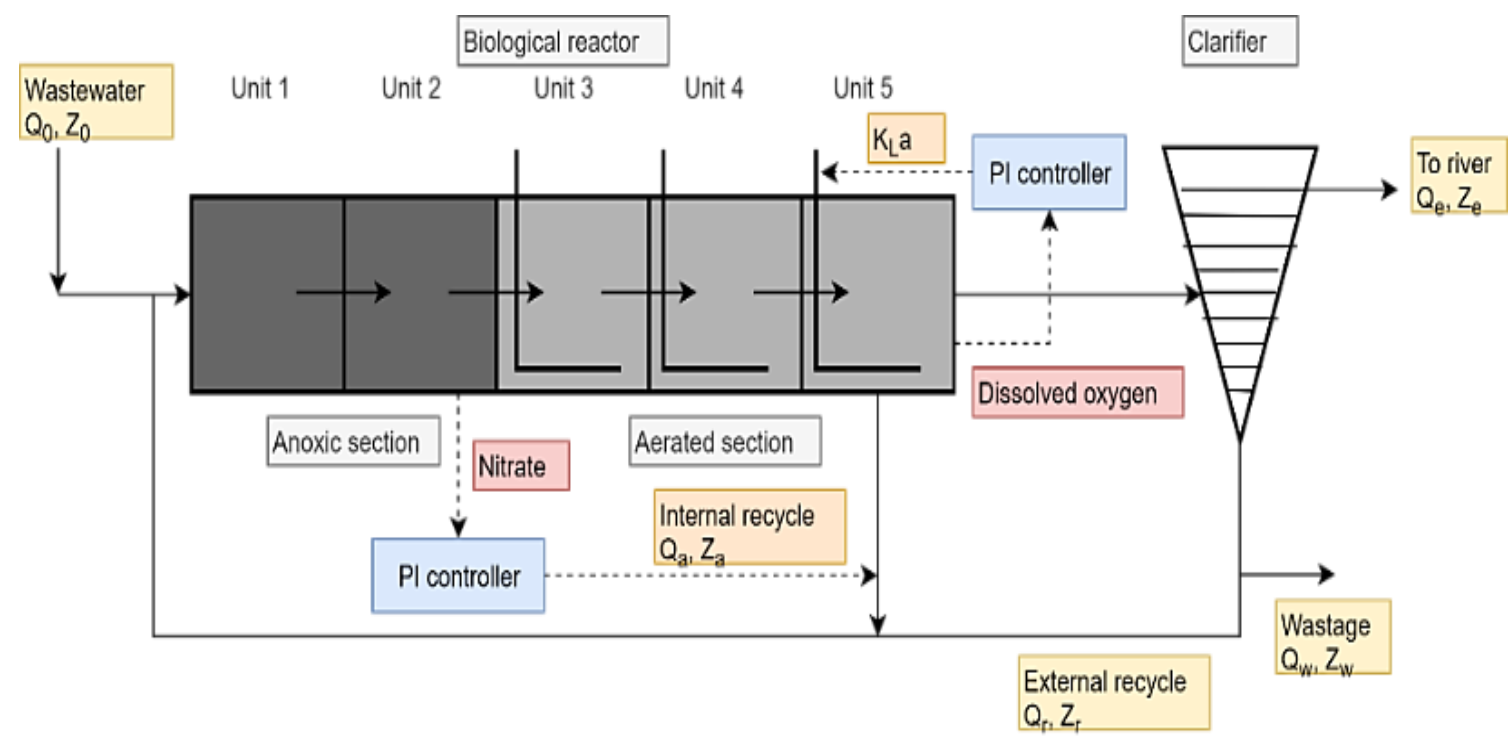

${ }^{*} K_{L} a=0 x y g e n$ transfer coefficient

Figure 1. The plant layout of the BSM1

In the BSM1 closed-loop assessment instance, the control handles are the oxygen transfer rate $\left(\mathrm{KL}_{\mathrm{a}}\right)$ in compartment number $5, \mathrm{KL}_{\mathrm{a} 5}$ and internal recirculation flow rate $\left(\mathrm{Q}_{\mathrm{a}}\right)$ [6]. The controller used in the BSM1 is the PI controller. PID is one of the most frequently applied control strategies in the WWTP due to its simplicity, robustness and close to optimum control performances. In the PI controller, the controller tries to reduce the inaccuracy by fine-tuning the process control input. A lot of research has been done on the existing BSM1 control handles, in terms of proposing a better control of DO [7-11], nitrate [12, 13] or both [14-16]. These research focus on developing a better controller, usually a more advanced one to fulfill the more stringent effluent standards set for all wastewater treatment plant. For the execution of alternative control schemes on the benchmark plant, few control handles are considered to exist. These include anoxic/aerobic volume, aeration intensity individually for each reactor $\left(\mathrm{KL}_{\mathrm{a} 1}, \mathrm{KL}_{\mathrm{a} 2}, \mathrm{KL}_{\mathrm{a} 3}, \mathrm{KL}_{\mathrm{a} 4}, \mathrm{KL}_{\mathrm{a} 5}\right)$, external carbon source flow rate $\left(\mathrm{q}_{\mathrm{EC} 1}, \mathrm{q}_{\mathrm{EC} 2}, \mathrm{q}_{\mathrm{EC} 3}, \mathrm{q}_{\mathrm{EC} 4}, \mathrm{q}_{\mathrm{EC} 5}\right)$, influent distribution by use of step feed $\left(f_{\text {Qinflow1 }}, f_{\text {Qinflow2 }}, f_{\text {Qinflow3 }}, f_{\text {Qinflow4 }}, f_{\text {Qinflow5 }}\right)$, distribution of internal flow recirculation $\left(f_{Q a 1}, f_{Q 22}, f_{Q a 3}, f_{Q a 4}, f_{Q a 5}\right)$, return sludge flow rate $\left(\mathrm{Q}_{\mathrm{r}}\right)$, wastage flow rate $\left(\mathrm{Q}_{\mathrm{w}}\right)$, and distribution of return sludge flow $\left(\mathrm{f}_{\mathrm{Qr} 1}, \mathrm{f}_{\mathrm{Qr} 2}, \mathrm{f}_{\mathrm{Qr} 3}, \mathrm{f}_{\mathrm{Qr} 4}\right.$, $\mathrm{f}_{\mathrm{Qr} 5}$ ). The few control handles considered to exist on the BSM1 are shown in Figure 2. However, there are limits to different control handles. 


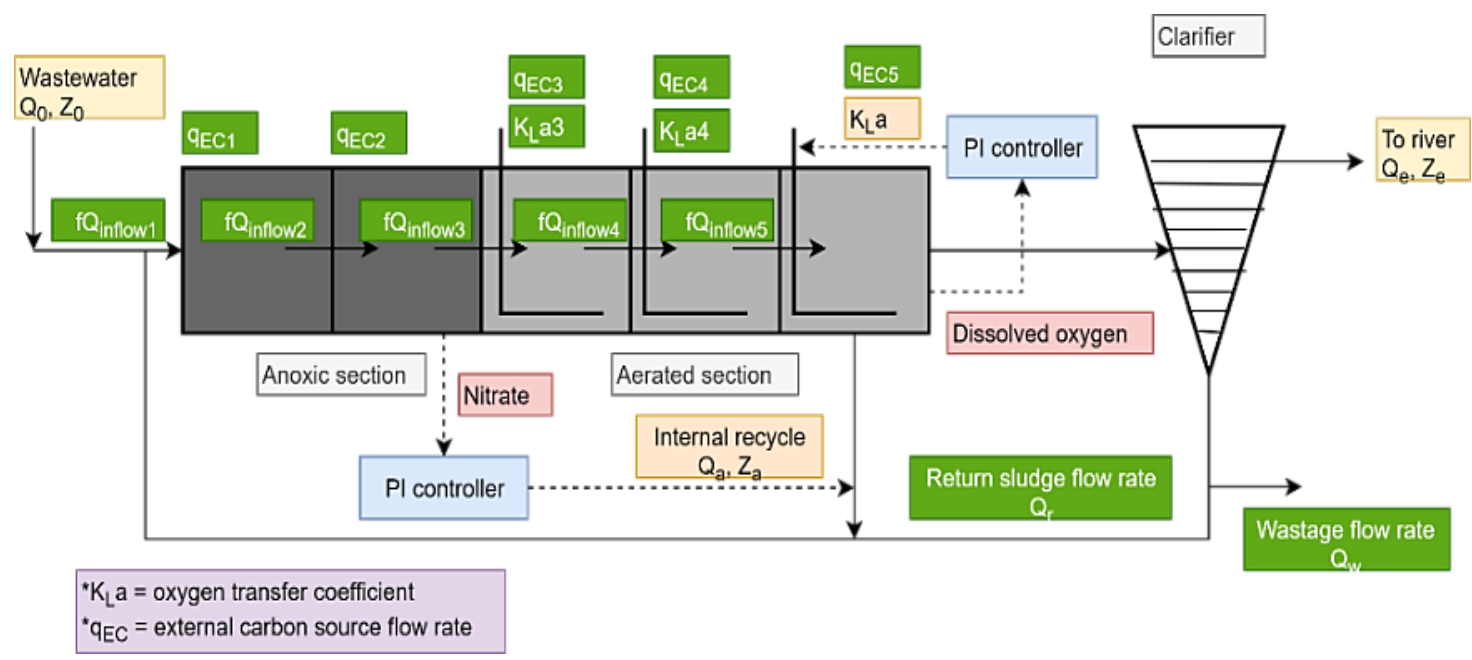

Figure 2. A few control handles considered to exist on the BSM1

Nonetheless, too many control handles may not be workable for the actual plant. Still, the abovementioned control handles are outlined for BSM1, to take for mostly any kind of common control approach. Some of the studies were performed on a few control handles other than the default one. But, there are only a few studies are found on individual aeration intensity control [16, 17], and external carbon source [18-20]. Nevertheless, the previous work [16] is performed with different DO setpoint configurations, [17] is using cascade control structure [18], [20] is not using BSM1 and [19] is using the COST simulation benchmark [21]. The WWTP is naturally a system with a multivariable and usually, this kind of system is defined using several control loops. Variations in any input values will commonly influence the outputs due to the relations between the inputs and outputs variables. Thus, in this study, a decentralized controller is used instead of a multivariable controller. A decentralized controller is an uncomplicated approach where the controlled plant is made up of a group of detached sub plants where every section in the plant is created individually.

The decentralized PI controller in WWTP can be found in a few papers [3], [22-24]. In [23], an adaptive interaction algorithm is developed together with a decentralized PI controller which targets to auto-tune the PI control parameters. It is examined that the decentralized PI controller with a tuning algorithm is effectively trailing the anticipated set point with substantial results. In [3], an adaptive decentralized PI controller is developed to satisfy the effluent quality and improving the nitrogen elimination for nonlinear activated sludge WWTP. The present work proposes three alternative control handles namely, the aeration intensity for individual reactor, external carbon source flow rate and combination of both. For all proposed alternative control handles, it is using a decentralized control structure. For the first control handle, three PI controllers are used for manipulating the $\mathrm{KL}_{\mathrm{a} 3}-\mathrm{KL}_{\mathrm{a} 5}$. In this control handles, it focusses on the enhancement of the ASP concerning DO concentration in all the aerated tanks. In the second proposed control handle which is the external carbon source, a fixed value of carbon source flow rate is investigated. The external carbon sources will affect the denitrification process in the activated sludge system [25]. As for a comparison, BSM1 standard control handles are used. In BSM1, the aeration intensity for tank 1 and 2 are: $\mathrm{KL}_{\mathrm{a} 1}$ and $\mathrm{KL}_{\mathrm{a} 2}=0 \mathrm{~h}^{-1}$ while for tank 3 and 4 are: $\mathrm{KL}_{\mathrm{a} 3}$ and $\mathrm{KL}_{\mathrm{a} 4}$ fixed at $10 \mathrm{~h}^{-1}=240 \mathrm{~d}^{-1}$. As for external carbon source flow rate for BSM1: $\mathrm{q}_{\mathrm{EC} 1}=\mathrm{q}_{\mathrm{EC} 2}=\mathrm{q}_{\mathrm{EC} 3}=\mathrm{q}_{\mathrm{EC} 4}=\mathrm{q}_{\mathrm{EC} 5}=0 \mathrm{~m}^{3} \cdot \mathrm{d}^{-1}$. As mentioned previously, the BSM1 recommends a PI control scheme. The closed-loop control arrangement comprises of a PI that controls the DO level in the $5^{\text {th }}$ compartment of the reactor at a predetermined setpoint value of $2 \mathrm{~g}(-\mathrm{COD}) \cdot \mathrm{m}^{-3}$ by manipulation of the $\mathrm{K}_{\mathrm{La} 5}$ and the $\mathrm{NO}_{3}-\mathrm{N}$ (nitrate) concentration in the second compartment at a predetermined setpoint value of $1 \mathrm{~g} . \mathrm{m}^{-3}$ by manipulation of the $\mathrm{Q}_{\mathrm{a}}$.

\section{RESEARCH METHOD}

The alternative control handles are divided into three case studies, case A: individual aeration intensity control, case B: addition of external carbon and case C: the combination of cases A and B.

\subsection{Case A: Individually control aeration intensity}

The first control case (A) is the DO control in three aeration zones, meaning that the aeration intensity for reactor 3-5 are individually controlled by one controller each. For the decentralized control structure, the WWTP is subdivided into three single input single output (SISO) subsystems, which made up 
the three PI controllers. The implementation of this control structure where a proportional-integral (PI) controller for each tank (3 to 5) is shown in Figure 3. The concentration of DO at the end of each aerobic tanks are computed and contrasted with the desired DO set point, which is supposed to have the standard value of $2 \mathrm{mg} \mathrm{O} / \mathrm{L}$. The individual controlled aeration intensity is proposed to help reduce the operational cost and better achieved effluent quality. The concentration of DOs in tank 3-5 are all set to $2 \mathrm{mg} / \mathrm{l}$. The control signal for all three PI controllers used for manipulating the $\mathrm{KL}_{\mathrm{a} 3}-\mathrm{KL}_{\mathrm{a} 5}$ is according to the following equation:

$$
u(t)=K_{p} e(t)+K_{i} \int_{0}^{t} e(t) d t
$$

Where $\mathrm{K}_{\mathrm{p}}$ and $\mathrm{K}_{\mathrm{i}}$ are the proportional and integral coefficients of the PI controller, correspondingly. The $\mathrm{K}_{\mathrm{p}}$ and $\mathrm{K}_{\mathrm{i}}$ are set to 25 and 25000 , respectively for each PI controller. Besides, the $\mathrm{KL}_{\mathrm{a} 3}$ - KLa5 are constrained to a maximum of $360 \mathrm{day}^{-1}$. As for nitrate concentration control in tank 2, the nitrate set point is set to $1 \mathrm{mg} / \mathrm{l}$. The $\mathrm{K}_{\mathrm{p}}$ and $\mathrm{K}_{\mathrm{i}}$ are set to 10000 and 800000, respectively. The Qa is constrained up to 5 times of stabilized input flow rate, $92230 \mathrm{~m}^{3}$ day $^{-1}$

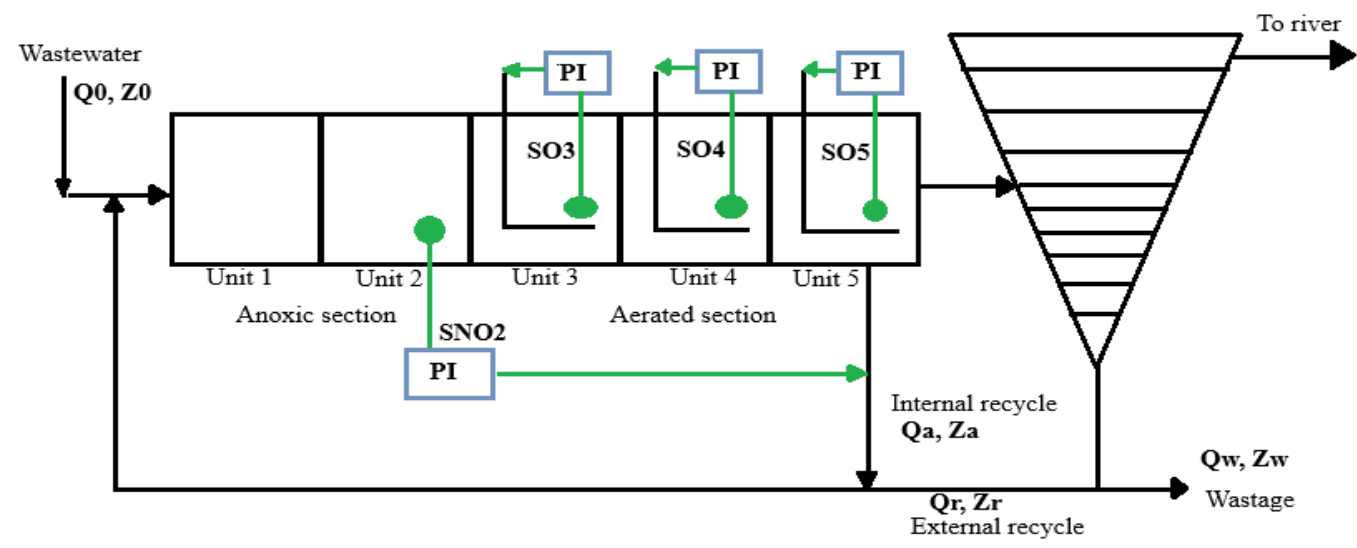

Figure 3. Individual aeration intensity control set up

\subsection{Case B: Fixed external carbon addition}

Case B is a fixed external carbon addition in the foremost anoxic tank reactor with configuration as shown in Figure 4. The value for carbon source is set at fixed at $0.25 \mathrm{~m}^{3} \cdot \mathrm{d}^{-1}$. The second control strategy is proposed for the reduction of effluent violation percentage. The value for carbon source is preferred to be small so that the cost for additional carbon dosage would not be that too large.

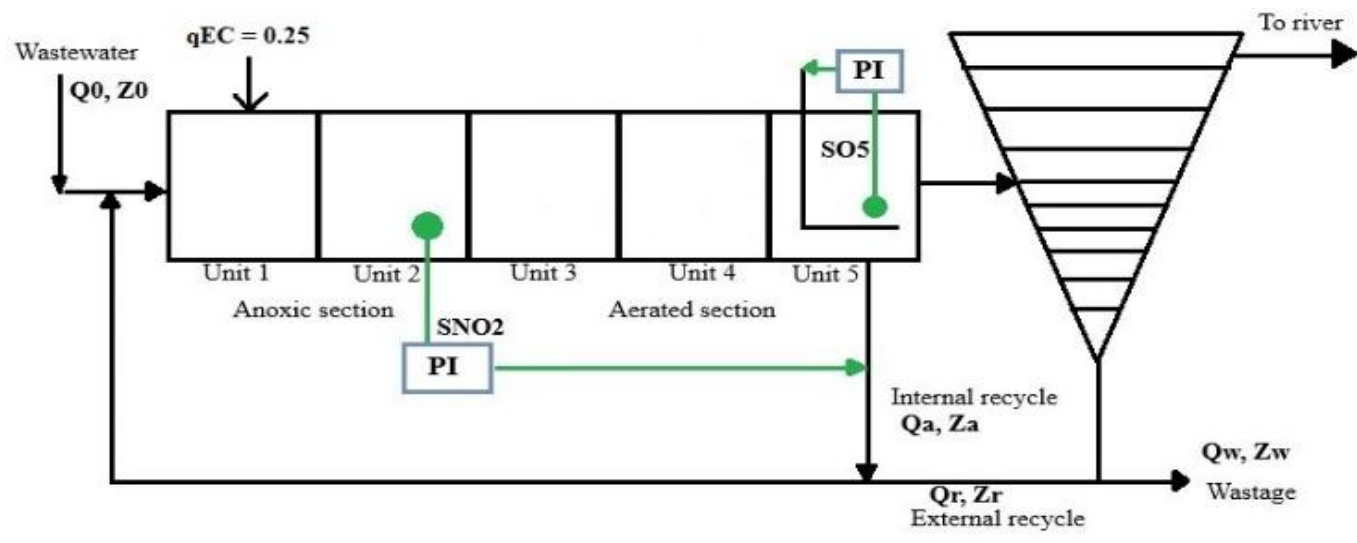

Figure 4. Fixed external carbon addition set up

\subsection{Case C: Combination of individually control aeration intensity and fixed carbon source addition}

The last case (C) is a combination of A and B strategies, with configuration as shown in Figure 5. The decentralized PI control together with carbon source addition configuration is predicted to produce a much lower total cost as compared to case B. 


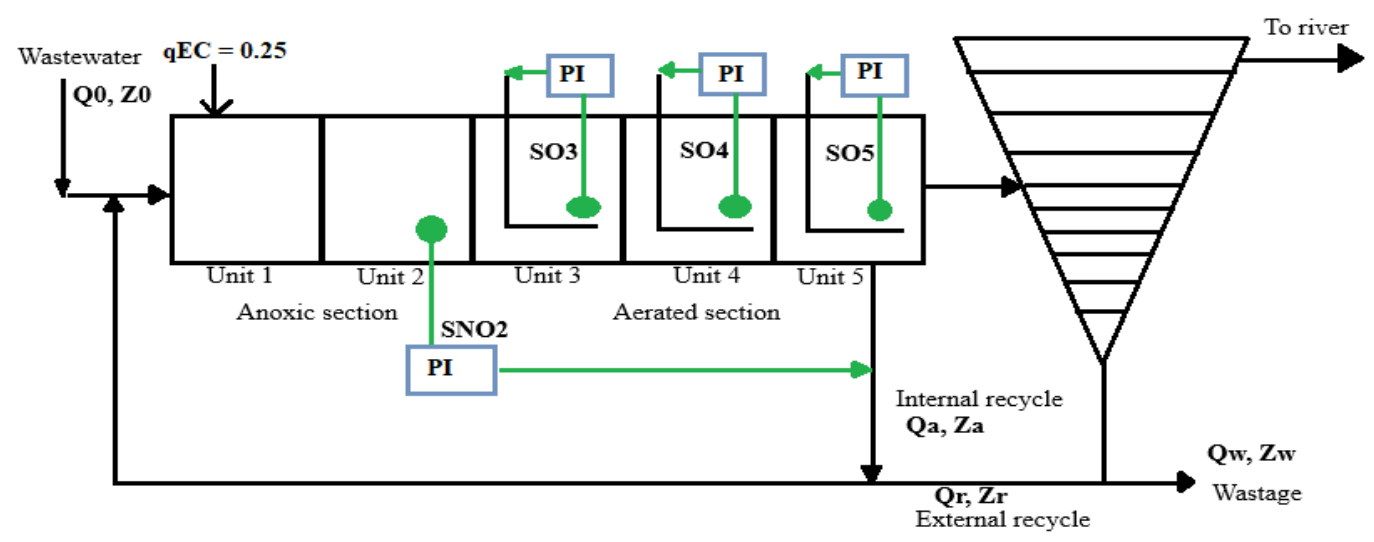

Figure 5. Individual aeration intensity control with a fixed external carbon addition set up

The performance assessment specifies quantifies for the outcome of the control approach on plant performance including the effluent quality, the cost factors for operations, overall cost index (OCI) and the measurement of an interval that the effluent maximums are violated. The effluent concentrations across the three assessment stages (weathers-dry/rain/storm) should follow the thresholds given in Table 1.

Table 1. The effluent quality limit

\begin{tabular}{cccccc}
\hline Variable & SNH & TSS & Ntot & CODt & BOD5 \\
\hline Value & $<4 \mathrm{~g} \mathrm{~N}^{-3} \mathrm{~m}^{-3}$ & $<30 \mathrm{~g} \mathrm{SS}^{-3}$ & $<18 \mathrm{~g} \mathrm{~N}^{-3} \mathrm{~m}^{-3}$ & $<100 \mathrm{~g} \mathrm{COD} \cdot \mathrm{m}^{-3}$ & $<10 \mathrm{~g} \mathrm{BOD}^{-3}$ \\
\hline
\end{tabular}

\section{RESULTS AND DISCUSSION}

The simulation procedure for BSM1 can be checked in [6]. At first, the BSM1 is simulated for 150 days using the constant influent input, which ideally is a procedure to attain a quasi-steady-state. This procedure is executed to assure that all the initial conditions of the states are consistent with the reading obtained from the BSM1 manual. The next step is to continue with setting-up the plant for the dynamic benchmark simulation by executing a 14-day simulation of dry influent. Lastly, the BSM1 is run for the 14 days of the dynamic test input weather (dry, rain or storm weather) with the presence of noise. For all the aeration intensity control, the DO sensor is of class A with a measurement range of 0 to $10 \mathrm{~g}(-\mathrm{COD}) \cdot \mathrm{m}^{-3}$ and measurement noise of $0.25 \mathrm{~g}(-\mathrm{COD}) \cdot \mathrm{m}^{-3}$ is used. As for nitrate control, the sensor is of class B0 with a measurement range of 0 to $20 \mathrm{~g} \mathrm{~N} . \mathrm{m}^{-3}$ and a measurement noise of $0.5 \mathrm{~g} \mathrm{~N} . \mathrm{m}^{-3}$.

The main aims of an activated sludge process control strategy are to minimize the operational cost and to keep the effluent concentrations within the regulation limits. Since tanks 1 and 2 of BSM1 are nonreacted compartments, no aeration control is performed at these two reactors. Three individual KLa control for reactor 3-5 is proposed to control the aerated tank 3-5. It is expected that the aeration energy cost will be lower than only KLa5 control and no-change or a slightly better effluent quality is expected since there is no additional controller for nitrate control.

\subsection{Average effluent violation}

The controller assessment examines the outcome of the proposed control scheme on the plant process. Initially, the performance of the average effluent violation is evaluated to the default benchmark, BSM1. The comparative results of effluent violation in dry and storm weather are shown in Table 2. From five key process variables that are evaluated, two variables which are total ammonia (SNH) and total nitrogen $\left(\mathrm{N}_{\text {tot }}\right)$ showed improved results in dry and storm influent, mainly using case A and C. The pollutants ammonia and $\mathrm{N}_{\text {tot }}$ are the parameters that are more challenging to be held below the determined boundaries [26]. A better $\mathrm{N}_{\text {tot }}$ removal is achieved through individually aeration control, thereby improving denitrification. The other process variables that are also evaluated show a small rise in the average effluent violation value as compared to BSM1 standard control handles. It can be observed that strategy is case A can reduce the SNH effluent violation in dry by $4 \%$ and in storm weather by $2 \%$. Addition of fixed external carbon at $0.25 \mathrm{~m}^{3} . \mathrm{d}^{-1}$ has shown a reduction of $3 \%$ of $\mathrm{N}_{\text {tot }}$ effluent violation in both kinds of weather. More reduction of $\mathrm{N}_{\text {tot }}$ effluent violation in both kinds of weather is achieved using Case $\mathrm{C}$ strategy. 


\begin{tabular}{|c|c|c|c|c|c|}
\hline Effluent average & $\begin{array}{c}\text { SNH } \\
\left(<4 \mathrm{~g} \mathrm{~N}^{-\mathrm{m}^{-3}}\right)\end{array}$ & 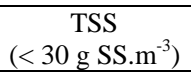 & $\begin{array}{c}\text { Ntot } \\
\left(<18 \mathrm{~g} \mathrm{~N}^{-3} \mathrm{~m}^{-3}\right)\end{array}$ & $\begin{array}{c}\text { CODt } \\
\left(<100{\left.\mathrm{~g} \mathrm{COD} . \mathrm{m}^{-3}\right)}^{-}\right.\end{array}$ & $\begin{array}{c}\text { BOD5 } \\
\left(<10 \mathrm{~g} \mathrm{BOD} \cdot \mathrm{m}^{-3}\right)\end{array}$ \\
\hline \multicolumn{6}{|l|}{ Dry } \\
\hline BSM1 & 2.4783 & 13.0248 & 16.8908 & 48.2470 & 2.7587 \\
\hline A & $2.3743 \boldsymbol{\nabla}$ & 13.0252 & $16.8685 \nabla$ & $48.2459 \nabla$ & $2.7585 \nabla$ \\
\hline B & 2.5196 & 13.0739 & $16.2733 \boldsymbol{\nabla}$ & 48.3192 & 2.7822 \\
\hline $\mathrm{C}$ & $2.4136 \nabla$ & 13.0743 & $16.2443 \nabla$ & 48.3180 & 2.7819 \\
\hline \multicolumn{6}{|l|}{ Storm } \\
\hline BSM1 & 2.9953 & 15.2935 & $15.8340 \boldsymbol{\nabla}$ & 47.6875 & 3.2065 \\
\hline A & $2.9318 \nabla$ & 15.2941 & $15.7840 \nabla$ & 47.6878 & 3.2066 \\
\hline B & 3.0272 & 15.3393 & $15.3034 \nabla$ & 47.7540 & 3.2306 \\
\hline $\mathrm{C}$ & $2.9613 \boldsymbol{\nabla}$ & 15.3400 & $15.2493 \nabla$ & 47.7543 & 3.2306 \\
\hline
\end{tabular}

\subsection{Number of effluent violations}

Table 3 shows the comparative results of several effluent violations using three different control case studies in dry and storm weather. It can be seen that using case $A$, the number of $\mathrm{N}_{\text {tot }}$ violation was reduced by $5 \%$ in storm weather and the number of SNH violation was reduced by $5 \%$ in both dry and storm weather. The addition of a fixed external carbon source has greatly reduced the number of $\mathrm{N}_{\text {tot }}$ violation by $27 \%$ in dry, and $30 \%$ in storm weather. However, the number of SNH violation is slightly increased using this B strategy (3\% in dry, and $1 \%$ in storm weather). The combination of A and B has improved this, with a reduction of the number of $\mathrm{SNH}$ violation is $3 \%$ in dry and storm weather while maintaining the same number of $\mathrm{N}_{\text {tot }}$ violation in both kinds of weather.

External carbon sources can improve the denitrification rate and hence decrease the nitrate level. It can be observed from Figure 6. that in dry weather, strategy B (blue line) and C (yellow line) show a huge reduction in Ntot violation as compared to BSM1 (black line) and strategy A (red line). In BSM1 and A, the limit was breached at seven different instances while for B and $\mathrm{C}$, the limit was violated at only five different occasions. It is observed from this study that the reduction of $\mathrm{N}_{\text {tot }}$ peaks is accomplished by adding additional external carbon dosage in the first tank. As for ammonia violation, as can be observed from Figure 7 (using storm weather), A (red line) and $\mathrm{C}$ (yellow line) showed a slightly better ammonia violation compared to BSM1 (black line). The strategy in case B (blue line) does not reduce the SNH violation, and in the case when the external carbon is added in dry and storm weather, SNH value is increased.

Table 3. The average effluent violation

\begin{tabular}{|c|c|c|c|c|c|c|}
\hline \multirow[t]{2}{*}{ Effluent violation limit } & \multicolumn{2}{|c|}{$\begin{array}{c}\text { Ntot } \\
(<18 \mathrm{mg} \mathrm{N} / \mathrm{l})\end{array}$} & \multicolumn{2}{|c|}{$\begin{array}{c}\mathrm{SNH} \\
(<4 \mathrm{mg} \mathrm{N} / \mathrm{l})\end{array}$} & \multicolumn{2}{|c|}{$\begin{array}{c}\text { TSS } \\
(<30 \mathrm{mg} \mathrm{SS} / \mathrm{l})\end{array}$} \\
\hline & Days & $\%$ & Days & $\%$ & Days & $\%$ \\
\hline \multicolumn{7}{|l|}{ Dry } \\
\hline BSM1 & 1.2500 & 17.86 & 1.1771 & 16.82 & - & - \\
\hline A & 1.2500 & 17.86 & $1.1146 \nabla$ & $15.92 \nabla$ & - & - \\
\hline $\mathrm{B}$ & $0.9167 \nabla$ & $13.10 \nabla$ & 1.2083 & 17.26 & - & - \\
\hline $\mathrm{C}$ & $0.9271 \nabla$ & $13.24 \nabla$ & $1.1458 \nabla$ & $16.37 \nabla$ & - & - \\
\hline \multicolumn{7}{|l|}{ Storm } \\
\hline BSM1 & 1.0833 & 15.48 & 1.8438 & 26.34 & 0.0208 & 0.30 \\
\hline A & $1.0313 \nabla$ & $14.73 \nabla$ & $1.7604 \nabla$ & $25.00 \nabla$ & 0.0208 & 0.30 \\
\hline B & $0.7604 \nabla$ & $10.86 \nabla$ & 1.8542 & 26.49 & 0.0208 & 0.30 \\
\hline $\mathrm{C}$ & $0.7500 \nabla$ & $10.71 \nabla$ & $1.7917 \mathbf{\nabla}$ & $25.60 \nabla$ & 0.0208 & 0.30 \\
\hline
\end{tabular}

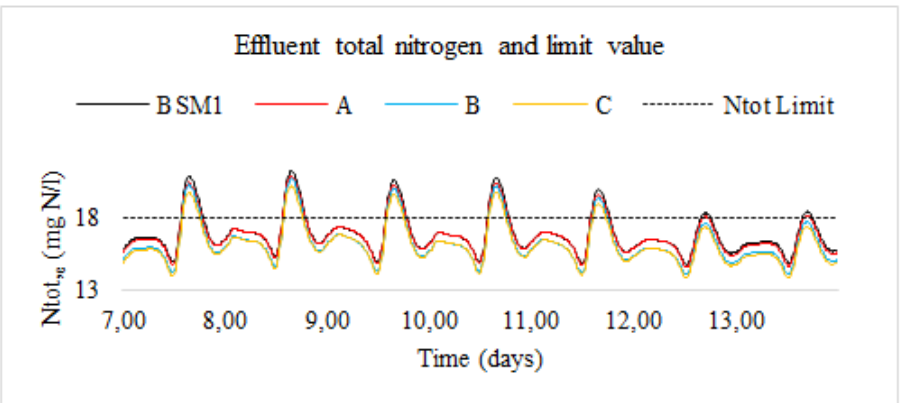

Figure 6. Comparison of total nitrogen violation for control strategies A, B, C and BSM1 


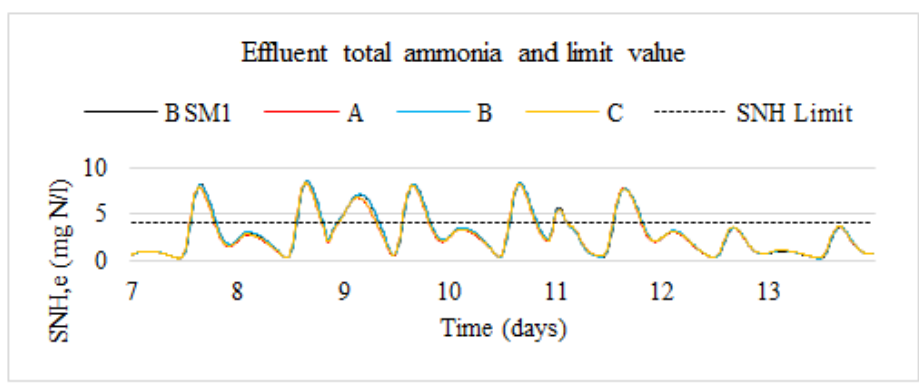

Figure 7. Comparison of ammonia violation for control strategies A, B, C and BSM1

\subsection{Effluent quality and operational cost}

Table 4 shows the effluent quality and cost for dry weather. A better effluent quality index is achieved as compared to BSM1. However, the lowest aeration energy consumed is obtained using strategy in case A. The results show that strategy in case A, which is individual control for reactor tank 3 to 5 display good improvement in the aeration energy which is lower by $4 \%$ as weigh against to the BSM1 control strategy.

Table 4. The effluent quality and cost (dry weather)

\begin{tabular}{|c|c|c|c|c|c|c|c|}
\hline+ & BSM1 & $\mathrm{A}$ & & B & & $\mathrm{C}$ & \\
\hline Effluent Quality (E.Q) index & 6096.71330 & 6054.87430 & $-1 \%$ & 6008.16450 & $-1 \%$ & 5964.35840 & $-2 \%$ \\
\hline Aeration energy cost index & 3697.5737 & 3534.4583 & $-4 \%$ & 3706.8623 & $0 \%$ & 3545.5703 & $-4 \%$ \\
\hline Total OCI & 16366.2631 & 16203.3652 & $-1 \%$ & 16853.5017 & $3 \%$ & 16692.3536 & $2 \%$ \\
\hline
\end{tabular}

It is well known that the most effective solutions to increase denitrification and to manipulate the nitrate recirculation flow rate is to add-on an external carbon source into the anoxic part of the process [12]. In cases $\mathrm{B}$ and $\mathrm{C}$ where the additional fixed carbon is introduced at tank 1, it is observed that effluent quality is better compared to BSM1. The case B strategy costs more compared to BSM1 and strategy in case $\mathrm{A}$. In the case of $\mathrm{C}$, the overall Total $\mathrm{OCI}$ is reduced by $1 \%$ as compared to the strategy proposed in case $\mathrm{B}$.

\section{CONCLUSION}

Three alternatives control handles for BSM1 are proposed and compared to BSM1 control handles to evaluate its' effectiveness. Case A has a better effluent quality index and much lower aeration energy and total OCI compared to BSM1. The aeration energy cost index is lower by $4 \%$ and total OCI is reduced by $1 \%$ overall. The effluent quality index is $1 \%$ better than the BSM1. As for case B, significant improvement in terms of reduction in the number of Ntot violation is achieved as a result of the addition of a fixed external carbon source for tank 1. Using a strategy in case B alone, the total OCI is increased by $3 \%$. The introduction of strategy in case $\mathrm{C}$ has shown a slight improvement recorded, where the aeration energy is lower by $4 \%$ and effluent quality is better by $2 \%$ when compared to BSM1. To conclude, the main objectives of this study are achieved which is to propose alternative strategies that minimize the operational cost and to keep the effluent concentrations within the limits.

\section{ACKNOWLEDGEMENTS}

The authors wish to thank the Ministry of Education Malaysia, Universiti Teknologi Malaysia and FRGS vote R.J130000.7811.4F817 for their financial support. Their support is gratefully acknowledged.

\section{REFERENCES}

[1] W. A. M. Ghoneim, A. A. Helal and M. G. Abdel Wahab, "Minimizing energy consumption in Wastewater Treatment Plants," 20163 rd International Conference on Renewable Energies for Developing Countries (REDEC), Zouk Mosbeh, pp. 1-8, 2016

[2] N. S. A. Yasmin, N. A. Wahab, A. N. Anuar, and M. Bob, "Performance comparison of SVM and ANN for aerobic granular sludge," Bulletin of Electrical Engineering and Informatics, vol. 8, no. 4, pp. 1392-1401, 2019. 
[3] M. F. Rahmat, S. I. Samsudin, N. A. Wahab, M. C. Razali, and M. S. Gaya, "Decentralized adaptive PI with adaptive interaction algorithm of wastewater treatment plant," Jurnal Teknologi Sciences Engineering vol. 67 , no. 5, pp. 15-21, 2014.

[4] G. G. Raju and S. M. Ali, "Fuzzy Based Gain Scheduled PI Controller for an Isolated Wind Diesel Hybrid Power System," Bulletin of Electrical Engineering and Informatics, vol. 1, no. 3, pp. 213-224, 2012.

[5] J. Ebegbulem, M. Guay, J. M. House, and T. I. Salsbury, "Decentralized Proportional-Integral Extremum Seeking Control for Heating, Ventilation and Air Conditioning (HVAC) Systems," 2018 IEEE Conference on Control Technology and Applications (CCTA), Copenhagen, pp. 800-805, 2018.

[6] J. Alex et al., "Benchmark Simulation Model no . 1 ( BSM1 )," pp. 1-58, 2008.

[7] H.-G. Han, J.-F. Qiao, and Q.-L. Chen, "Model predictive control of dissolved oxygen concentration based on a self-organizing RBF neural network," Control Engineering Practice vol. 20, no. 4, pp. 465-476, April 2012.

[8] G. Harja, G. Vlad, and I. Nascu, "MPC advanced control of dissolved oxygen in an activated sludge wastewater treatment plant," 2016 IEEE International Conference on Automation, Quality and Testing, Robotics (AQTR), ClujNapoca, pp. 1-6, 2016.

[9] C. A. C. Belchior, R. A. M. Araújo, and J. A. C. Landeck, "Dissolved oxygen control of the activated sludge wastewater treatment process using stable adaptive fuzzy control," Computers \& Chemical Engineering, vol. 37, pp. 152-162, Feb 2012.

[10] B. Holenda, E. Domokos, and J. Fazakas, "Dissolved oxygen control of the activated sludge wastewater treatment process using model predictive control," Computers \& Chemical Engineering, vol. 32, no. 6, pp. 1270-1278, 2008.

[11] H.-G. Han and J.-F. Qiao, "Adaptive dissolved oxygen control based on dynamic structure neural network," Applied Soft Computing, vol. 11, no. 4, pp. 3812-3820, June 2011.

[12] W. Shen, E. Tao, X. Chen, D. Liu, and H. Liu, "Nitrate control strategies in an activated sludge wastewater treatment process," Korean Journal Chemical Engineering, vol. 31, no. 3, pp. 386-392, Feb 2014.

[13] M. Ekman, P. Samuelsson, and B. Carlsson, "Adaptive control of the nitrate level in an activated sludge process.," Water Science \& Technology, vol. 47, no. 11, pp. 137-44, Jan 2003.

[14] W. Shen, X. Chen, and J. P. Corriou, "Application of model predictive control to the BSM1 benchmark of wastewater treatment process," Computers \& Chemical Engineering, vol. 32, no. 12, pp. 2849-2856, Dec 2008.

[15] S. Revollar, P. Vega, R. Vilanova, and M. Francisco, "Optimal Control of Wastewater Treatment Plants Using Economic-Oriented Model Predictive Dynamic Strategies,” Appl. Sci., vol. 7, no. 8, p. 813, 2017.

[16] I. Nascu and I. Nascu, "Improving Activated Sludge Wastewater Treatment Process Efficiency Using Predictive Control," Adv. Technol. Innov., vol. 3, no. 2, pp. 59-69, 2018.

[17] M. Várhelyi, M. Brehar, and V. M. Cristea, "Control strategies for wastewater treatment plants aimed to improve nutrient removal and to reduce aeration costs," 2018 IEEE International Conference on Automation, Quality and Testing, Robotics (AQTR), Cluj-Napoca, pp. 1-6, 2018.

[18] C.-F. Lindberg and B. Carlsson, "Adaptive control of external carbon flow rate in an activated sludge process," Water Science and Technology, vol. 34, no. 3-4, pp. 173-180, 1996.

[19] J. H. Cho, S. W. Sung, and I. B. Lee, "Cascade control strategy for external carbon dosage in predenitrifying process.," Water Science and Technology, vol. 45, no. 4-5, pp. 53-60, Jan 2002.

[20] Q. Wang, Q. Chen, and J. Chen, "Optimizing external carbon source addition in domestics wastewater treatment based on online sensoring data and a numerical model," Water Science and Technology, vol. 75, no. 11, pp. 2716-2725, 2017.

[21] J. Copp, "The COST Simulation Benchmark-Description and Simulator Manual," 2001.

[22] S. Strmcnik, Case Studies in Control, Putting Theory to Work, April. 2013.

[23] S. I. Samsudin, M. F. Rahrnat, N. A. Wahab, M. C. Razali, M. S. Gaya, and S. N. S. Salim, "A self-Tuning decentralized PI control for multivariable plant," 2012 IEEE International Conference on Control System, Computing and Engineering, Penang, pp. 100-104, 2012.

[24] X. Hongyang, C. Pedret, I. Santin, and R. Vilanova, "Decentralized model predictive control for N and P removal in wastewater treatment plants," 2018 22nd International Conference on System Theory, Control and Computing (ICSTCC), Sinaia, pp. 224-230, 2018.

[25] E. Liwarska-Bizukojć, J. Chojnacki, M. Klink, and D. Olejnik, "Effect of the type of the external carbon source on denitrification kinetics of wastewater," Desalination and Water Treatment, vol. 101, pp. 143-150, 2018.

[26] I. Santin, C. Pedret, M. Meneses, and R. Vilanova, "Process based control architecture for avoiding effluent pollutants quality limits violations in wastewater treatment plants," 2015 19th International Conference on System Theory, Control and Computing (ICSTCC), Cheile Gradistei, pp. 396-402, 2015. 